\title{
PENGARUH MASSAGE EFFLURAGE DENGAN VIRGIN COCONUT OIL (VCO) TERHADAP PENCEGAHAN DEKUBITUS PADA PASIEN BEDREST DI RUANG INSTALASI RAWAT INTENSIVE (IRIN) RS MARDI RAHAYU KUDUS
}

\author{
Santiko $^{1}$, Noor Faidah ${ }^{2}$ \\ 1,2Program Studi Keperawatan STIKES Cendekia Utama Kudus \\ Email : $\underline{\text { Santiko89@yahoo.com, mamiinung96@gmail.com }}$
}

\begin{abstract}
ABSTRAK
Salah satu faktor eksternal yang dapat menyebabkan gangguan integritas kulit adalah imobilisasi. Dampak buruk dari imobilisasi yaitu gangguan integritas kulit yang dapat mengakibatkan terjadinya iritasi dan luka tekan. Salah satu terapi pijat yang telah disebutkan diatas yaitu teknik massage efflurage dengan Virgin Coconut Oil (VCO) yang mana merupakan teknik mengusap sekali atau dua kali sehari efektif dalam mencegah luka tekan. Penelitian ini bertujuan untuk mengetahui pengaruh massage efflurage dengan Virgin Coconut Oil (VCO) terhadap pencegahan dekubitus pada pasien bedrest di Ruang Instalasi Rawat Intensive (IRIN) RS Mardi Rahayu. Jenis penelitian Quasi experimental design dengan rancangan control grup design pretest dan posstest. Populasi dalam penelitian ini yaitu semua pasien Bedrest yang dirawat di ruang Instalasi Rawat Intensive (IRIN). Teknik sampling menggunakan Purposive Sampling sehingga besar sampel 46 responden. Teknik analisa data menggunakan Chi Square. Sebelum dilakukan massage efflurage dengan VCO pada kelompok kontrol dan intervensi hasilnya sama tidak ada yang dekubitus dikarenakan responden yang dipilih sesuai dengan kriteria eklusi yaitu pasien tidak terjadi dekubitus. Sesudah dilakukan massage efflurage dengan VCO hasil menggunakan uji Chi Square menggunakan Fisher Exact diperoleh p-value 0,022. Terdapat pengaruh secara signifikan massage efflurage dengan Virgin Coconut Oil (VCO) terhadap pencegahan dekubitus pada pasien bedrest di Ruang Instalasi Rawat Intensive (IRIN) RS Mardi Rahayu Kudus.
\end{abstract}

Kata Kunci : Massage dengan Virgin Coconut Oil (VCO), Dekubitus

\section{ABSTRACT}

Immobilization is one of the external factor that cause skin integrity disorders, the negative impact of immobilization is the disruptions of skin that lead to the irritation and pressure wounds. One of massage therapy that can be used is massage efflurage technique with virgin coconut oil (VCO), which is applied with rubbing on the skin once or twice daily. This study aims to find the effect of massage efflurage with virgin coconut oil (VCO) to the perevention of decubitus in bedridden patient at the intensive care installation room (IRIN) Mardi Rahayu Kudus Hospital. The type of 
research is quasy experimental design with control group of pretest and posttest. Population of this research is all of bedridden patients at the intensive cara installation room (IRIN). The sampling technique uses purposive sampling so that the sample size is 46 respondens. The data analyzes technique uses chi square. Before the massage efflurage with VCO to the control group and after the intervention, there was same result, no incident of pressure sores was happened. Because the respondent congruent to the exclusion criteria, which is the patient without pressure sores. After the exposure of massage efflurage with VCO, used the Chi Square with Fisher Exact, the p value is 0,022 . There is a significant effect of massage efflurage with virgin coconut oil (VCO) to prevent the decubitus at bedridden patients in intensive care installation room (IRIN) Mardi Rahayu Hospital.

Keywords : Massage efflurage, Virgin Coconut oil (VCO), Dekubitus.

\section{LATAR BELAKANG}

Salah satu faktor eksternal yang dapat menyebabkan gangguan integritas kulit adalah imobilisasi. Imobilisasi adalah ketidakmampuan untuk bergerak bebas yang disebabkan oleh kondisi dimana gerakan tergganggu atau dibatasi secara terapeutik yang bisa berhubungan langsung dengan faktor internal seperti penyakit kronis atau status kesehatan (Potter \& Perry, 2010). Bedrest adalah ketidakmampuan untuk bergerak secara aktif akibat berbagai penyakit atau impairment (gangguan pada alat/ organ tubuh) yang bersifat fisik atau mental. Imobilisasi dapat juga diartikan sebagai suatu keadaan tidak bergerak / tirah baring yang terus - menerus selama 5 hari atau lebih akibat perubahan fungsi fisiologis. Di dalam praktek medis bedrest digunakan untuk menggambarkan suatu sindrom degenerasi fisiologis akibat dari menurunnya aktivitas dan ketidakberdayaan (Hidayat, 2010).

Dampak buruk dari imobilisasi yaitu gangguan integritas kulit yang dapat mengakibatkan terjadinya iritasi dan luka tekan (Potter \& Perry, 2010). Dampak lain bagi pasien yang dirawat lama di rumah sakit dengan keterbatasan aktivitas multiple and life threatening medical complications, yaitu meningkatkan durasi lama rawat atau length of stay (LOS). Hal ini akan meningkatkan beban terutama biaya rawat inap sesuai lama waktu perawatan (Morison, 2014). Pasien dengan bedrest rentan terjadi cedera akibat penurunan aliran darah dan resiko terjadinya ruam akibat dari hipersensitivitas, reaksi obat, atau infeksi oportunistik (Morton, et al., 2012). Komplikasi lain yang bisa terjadi pada pasien dengan bedrest adalah ulkus dekubitus. (Potter \& Perry, 2010).

Berdasarkan data dari profil kesehatan provinsi Jawa Tengah, Di RSUD Moewardi didapatkan 38,18\% pasien mengalami dekubitus (Wicaksana \& Priyogo, 2015). Di kabupaten Salatiga tahun 2016 tercatat 25 pasien yang mengalami dekubitus. Di RS Tlogorejo Semarang tahun 2017 ada 15 pasien (laporan indikator mutu). Data insiden dekubitus RS Mardi Rahayu tahun 2017 dari bulan Januari - Desember sebanyak 28 pasien (laporan indikator mutu PPI). Tahun 2018 antara bulan Januari - Desember sebanyak 35 pasien (laporan indikator mutu PPI).

Dekubitus atau sering dikenal dengan luka tekan adalah cedera yang terlokalisir pada kulit dan atau jaringan di bawahnya biasanya di atas tonjolan tulang, sebagai akibat adanya tekanan atau kombinasi dari tekanan dan gesekan (NPUAP-EPUAP, 2014). Sedangkan menurut Perry et al., (2012) dekubitus adalah luka pada kulit dan atau 
jaringan di bawahnya, biasanya disebabkan oleh adanya penonjolan tulang, sebagai akibat dari tekanan atau kombinasi tekanan dengan gaya geser dan atau gesekan. Ulkus dekubitus atau luka tekan adalah nekrosis jaringan lokal ketika jaringan lunak tertekan antara tonjolan tulang dengan permukaan eksternal dalam jangka waktu yang lama, karena tekanan atau akibat gaya gesek. Pencegahan dekubitus merupakan prioritas dalam perawatan pasien dan tidak terbatas pada pasien yang mengalami keterbatasan mobilisasi (Potter \& Perry, 2010). Untuk mengurangi kemungkinan perkembangan dekubitus pada semua pasien, perawat harus melakukan berbagai macam tindakan pencegahan, seperti perawat menjaga kebersihan kulit pasien, untuk mempertahankan integritas kulit, mengajarkan pasien dan keluarga untuk pencegahan dan memberikan asuhan keperawatan mengenai cara mencegah dekubitus (Kozier, 2010).

Pencegahan gangguan integritas kulit sangat penting dan dapat dilakukan dengan mengubah posisi pasien setiap dua jam disertai dengan massage. Massage merupakan intervensi keperawatan yang dapat diberikan kepada pasien imobilisasi untuk menjaga hidrasi kulit dalam batas wajar (Bambang, 2012). Terapi pijat (massage) merupakan upaya penyembuhan yang aman, efektif, dan tanpa efek samping (Firdaus, 2011).

Teknik yang diperbolehkan hanya efflurage namun tidak untuk jaringan di atas tulang yang menonjol maupun yang telah menunjukkan kemerahan ataupun pucat . lama waktu massage yang digunakan masih bervariasi antara 4 -5 menit (Eliis \& Bentz 2010). Menurut Bambang (2011), massage efflurage adalah suatu gerakan dengan mempergunakan seluruh permukaan telapak tangan melekat pada bagian tubuh yang digosok. Bentuk telapak tangan dan jari-jari selalu menyesuaikan dengan bagian tubuh yang digosok. Tangan menggosok secara supel atau gentel menuju kearah jantung (centrifugal) misalnya gosokan di dada, perut dan sebagainya.

Massage yang dilakukan dalam penelitian ini menggunakan virgin coconut oil (VCO), VCO sangat baik untuk kesehatan kulit, mengandung pelembab alami sehingga mudah diserap kulit, mengandung vitamin E yang dapat membantu menjaga kulit agar tetap lembut, halus, dan mengurangi risiko kanker kulit (Soekardi dam Yuliadi, 2012). Menurut Price dalam Handayani \& Ririn (2010), medium fatty acid yang terdapat pada VCO mengandung sabun yang sama seperti pada sabun kulit, terdapat lemak ilmiah yang menjadi antimikrobial pada kulit dan melindungi kulit dari infeksi.

Menurut Price Sylvia (2012), dalam VCO unsur antioksidan dan vitamin E masih dapat dipertahankan sehingga jika digunakan sebagai pelindung kulit akan mampu melembutkan kulit. Disamping mengandung asam laurat yang tinggi, VCO juga mengandung Vitamin E (Amin, 2010). Kandungan asam lemak (terutama asam laurat dan oleat) dalam VCO, sifatnya yang melembutkan kulit. Pelembab yang terbuat dari minyak kelapa murni cepat membangun hambatan mikrobial dan asam alami. Dengan demikian memakai minyak kelapa murni setelah mandi akan bermanfaat bagi kesehatan kulit dengan meningkatkan atau mempertahankan toleransi jaringan yang diharapkan.

Penelitian yang dilakukan oleh Handayani, et al. (2011) pemberian Virgin Coconut Oil (VCO) dengan massage efektif untuk digunakan dalam pencegahan dekubitus derajat I pada pasien yang berisiko mengalami dekubitus.

Berdasarkan hasil wawancara dengan Wakil Kepala Ruang Instalasi Rawat Intensive (IRIN) RS Mardi Rahayu intervensi yang sudah diterapkan untuk mencegah 
dekubitus pada pasien bedrest, yaitu perubahan posisi setiap dua -4 jam. VCO belum pernah diterapkan untuk mencegah gangguan dekubitus di ruang Instalasi Rawat Intensive (IRIN). Berdasarkan latar belakang tersebut, penulis tertarik melakukan penelitian pengaruh Massage Efflurage dengan Virgin Coconut Oil (VCO) terhadap kejadian dekubitus pada pasien bedrest di Ruang Instalasi Rawat Intensive (IRIN) Rumah Sakit Mardi Rahayu Kudus.

Penelitian ini bertujuan untuk menganalisa pengaruh massage efflurage dengan Virgin Coconut Oil (VCO) terhadap pencegahan dekubitus pada pasien bedrest di Ruang Instalasi Rawat Intensive (IRIN) RS Mardi Rahayu Kudus.

\section{METODE PENELITIAN}

Metode penelitian yang digunakan adalah Quasi experimental dengan desain control grup design pretest dan posstest. Populasi dalam penelitian ini yaitu semua pasien Bedrest yang dirawat diruang Instalasi Rawat Intensive (IRIN) didapatkan data dari bulan Oktober - Desember 2018 sejumlah 52 pasien. Teknik pengambilan sampel pada penelitian ini akan menggunakan purposive sampling. Berdasarkan penghitungan slovin bahwa besar sample sebanyak 46 orang, dibedakan 23 responden merupakan kelompok perlakuan dan 23 kelompok kontrol. Data diolah secara statistik menggunakan program komputer. Analisa data dalam penelitan ini adalah Chi Square.

\section{HASIL DAN PEMBAHASAN Analisa Univariat}

Tabel 1

Distribusi frekuensi responden berdasarkan jenis kelamin di Ruang IRIN RS Mardi Rahayu Kudus $(n=46)$

\begin{tabular}{lllllllc}
\hline Variabel & Kategori & \multicolumn{2}{l}{ Kelompol Intevensi } & \multicolumn{2}{l}{ Kelompok Kontrol } & \multicolumn{2}{c}{ Jumlah } \\
\cline { 2 - 7 } & & Frekuensi & Persentase & Frekuensi & Persentase & $\mathrm{n}$ & $\%$ \\
\hline Jenis & Laki & 10 & 43.5 & 11 & 47.8 & 21 & 45.7 \\
Kelamin & & & & & & & \\
& Perempuan & 13 & 56.5 & 12 & 52.2 & 25 & 54.3 \\
\hline Jumlah & & 23 & 100 & 23 & 100 & 46 & 100 \\
\hline
\end{tabular}

Tabel 1 menyajikan distribusi frekuensi responden berdasarkan karakteristik jenis kelamin yaitu pada kelompok intervensi responden yang berjenis kelamin laki-laki sebanyak 10 orang $(43.5 \%)$ dan berjenis kelamin perempuan sebanyak 13 orang $(56,5 \%)$ sedangkan responden kelompok kontrol yang berjenis kelamin laki-laki sebanyak 11 orang $(47.8 \%)$ dan berjenis kelamin perempuan sebanyak 12 orang $(52,2 \%)$. Jumlah keseluruhan responden yang berjenis kelamin lakilaki sebanyak 21 orang $(45.7 \%)$ dan berjenis kelamin perempuan sebanyak 25 orang $(54,3 \%)$ dari total responden keseluruhan yaitu 46 orang $(100 \%)$. 
Tabel 2

Distribusi frekuensi responden berdasarkan Usia di Ruang IRIN RS Mardi Rahayu Kudus $(n=46)$

\begin{tabular}{lllllll}
\hline Kategori & \multicolumn{2}{c}{ Kelompol Intevensi } & \multicolumn{2}{c}{ Kelompok Kontrol } & \multicolumn{2}{c}{ Jumlah } \\
\hline Usia & Frekuensi & Persentase & Frekuensi & Persentase & $\mathrm{n}$ & $\%$ \\
\hline$<60$ tahun & 8 & 34.8 & 11 & 47.8 & 21 & 41.3 \\
$>60$ tahun & 15 & 65.2 & 12 & 52.2 & 25 & 58.7 \\
\hline Jumlah & 23 & 100 & 23 & 100 & 46 & 100 \\
\hline
\end{tabular}

Tabel 2 menyajikan distribusi frekuensi responden berdasarkan karakteristik Usia yaitu pada kelompok intervensi responden yang usianya $<60$ tahun sebanyak 8 orang $(34.8 \%)$ dan kelompok kontrol $<60$ tahun sebanyak 11 orang $(47.8 \%)$ sedangkan responden pada kelompok intervensi yang usianya $>60$ tahun sebanyak 15 orang $(65.2 \%)$ dan kelompok kontrol sebanyak 12 orang $(52.2 \%)$. Jumlah keseluruhan responden yang usianya $<60$ tahun sebanyak 21 orang $(41.3 \%)$ dan responden yang usianya $>60$ tahun sebanyak 25 orang $(58,7 \%)$ dari total responden keseluruhan yaitu 46 orang $(100 \%)$.

Tabel 3

Distribusi Frekuensi Berdasarkan Kejadian Dekubitus Sebelum Diberikan Massage Efflurage dengan virgin coconut oil pada Kelompok Intervensi dan Kontrol

\begin{tabular}{lcccc}
\hline \multirow{2}{*}{ Kejadian Dekubitus } & \multicolumn{2}{c}{ Kelompok Intervensi } & \multicolumn{2}{c}{ Kelompok Kontrol } \\
\cline { 2 - 5 } & Frekuensi & Persentase (\%) & Frekuensi & Persentase (\%) \\
\hline Dekubitus & 0 & 0,0 & 0 & 0,0 \\
Tidak Dekubitus & 23 & 100,0 & 23 & 100,0 \\
\hline Jumlah & 23 & 100,0 & 23 & 100,0 \\
\hline
\end{tabular}

Berdasarkan tabel 3 dapat diketahui bahwa sebelum diberikan terapi massage efflurage dengan virgin coconut oil pada pasien kelompok intervensi, semuanya tidak mengalami kejadian dekubitus, sejumlah 23 orang (100\%). Begitu juga pada kelompok kontrol, semuanya juga tidak mengalami kejadian dekubitus, sejumlah 23 orang (100\%).

Tabel 4

Distribusi Frekuensi Berdasarkan Kejadian Dekubitus Sesudah Diberikan Massage Efflurage dengan VCO pada Kelompok Intervensi dan Kontrol

\begin{tabular}{lcccc}
\hline \multirow{2}{*}{ Kejadian Dekubitus } & \multicolumn{2}{c}{ Kelompok Intervensi } & \multicolumn{2}{c}{ Kelompok Kontrol } \\
\cline { 2 - 5 } & Frekuensi & Persentase (\%) & Frekuensi & Persentase (\%) \\
\hline Dekubitus & 1 & 4,3 & 8 & 34,8 \\
Tidak Dekubitus & 22 & 95,7 & 15 & 65,2 \\
\hline Jumlah & 23 & 100,0 & 23 & 100,0 \\
\hline
\end{tabular}

Berdasarkan tabel 4 dapat diketahui bahwa sesudah diberikan terapi massage efflurage dengan virgin coconut oil pada kelompok intervensi, sebagian besar pasien tidak mengalami kejadian dekubitus, sejumlah 22 orang $(95,7 \%)$, sedangkan pasien yang mengalami kejadian dekubitus sejumlah 1 orang $(4,3 \%)$. Pada kelompok kontrol yang tidak 
diberikan massage efflurage dengan Virgin Coconut Oil, sebagian besar pasien tidak mengalami kejadian dekubitus, sejumlah 15 orang $(65,2 \%)$, sedangkan pasien yang mengalami kejadian dekubitus sejumlah 8 orang $(34,8 \%)$.

Analisa Bivariat

Tabel 5

Perbedaan Kejadian Dekubitus antara Kelompok Intervensi dan Kontrol pada Pasien Bedrest di Rumah Sakit Mardi Rahayu Kudus

\begin{tabular}{|c|c|c|c|c|c|c|c|}
\hline \multirow{3}{*}{ Kelompok } & \multicolumn{6}{|c|}{ Kejadian Dekubitus } & \multirow{3}{*}{$\mathrm{p}$-value } \\
\hline & \multicolumn{2}{|c|}{ Dekubitus } & \multicolumn{2}{|c|}{$\begin{array}{c}\text { Tidak } \\
\text { Dekubitus }\end{array}$} & \multicolumn{2}{|c|}{ Total } & \\
\hline & $\mathrm{F}$ & $\%$ & $\mathrm{f}$ & $\%$ & $f$ & $\%$ & \\
\hline Intervensi & 1 & 4,3 & 22 & 95,7 & 23 & 100 & 0,022 \\
\hline Kontrol & 8 & 34,8 & 15 & 65,2 & 23 & 100 & \\
\hline Total & 9 & 19,6 & 37 & 80,4 & 46 & 100 & \\
\hline
\end{tabular}

Hasil pada tabel 5 dapat diketahui bahwa pada pasien kelompok intervensi yang diberikan massage efflurage dengan Virgin Coconut Oil, yang mengalami kejadian dekubitus hanya sejumlah 1 orang (4,3\%). Kejadian jauh ini lebih rendah dibandingkan pada kelompok kontrol yang tidak diberikan massage efflurage dengan Virgin Coconut Oil, yang mengalami kejadian dekubitus sejumlah 8 orang $(34,8 \%)$.

Hasil uji Chi Square menggunakan Fisher Exact diperoleh p-value 0,022. Oleh karena p-value $(0,022)<\alpha(0,05)$, , maka dapat disimpulkan bahwa ada pengaruh secara signifikan massage efflurage dengan Virgin Coconut Oil (VCO) terhadap pencegahan dekubitus pada pasien bedrest di Ruang Instalasi Rawat Intensive (IRIN) RS Mardi Rahayu Kudus.

\section{Karakteristik responden}

Karakteristik jenis kelamin responden paling banyak adalah perempuan 25 orang $54.3 \%$ terdiri dari kelompok intervensi 13 orang 56.5\% dan kelompok kontrol 12 orang $52.2 \%$. Jumlah laki - laki 21 orang $45.7 \%$ terdiri dari kelompok intervensi 10 orang $43.5 \%$ dan kelompok kontrol 11 orang $47.8 \%$ total $100 \%$.

Lebih banyaknya responden perempuan yang terlibat dalam penelitian ini dikarenakan selama penelitian dilakukan banyaknya pasien perempuan yang masuk Ruang IRIN, sehingga ketika pemilihan sampel dilakukan peluang sampel terpilih menjadi lebih besar untuk responden perempuan dibandingkan laki - laki.

Hasil penelitian ini menunjukkan pada kelompok intervensi diketahui usia $<60$ tahun 8 orang atau $34.8 \%$ pada kelompok kontrol 11 orang atau 47.8 total 19 pasien atau $41.3 \%$. Pada usia $>60$ tahun dalam kelompok intervensi ada 15 orang atau $65.2 \%$, kelompok kontrol 12 orang atau 52.2\%. Jadi responden lebih banyak pada kelompok usia $>$ 60 tahun. 
Kejadian Dekubitus Sebelum Diberikan massage efflurage dengan virgin coconut oil pada Kelompok Intervensi dan Kontrol.

Diketahui bahwa sebelum diberikan terapi massage efflurage dengan virgin coconut oil pada pasien kelompok intervensi, semuanya tidak mengalami kejadian dekubitus, sejumlah 23 orang (100\%). Begitu juga pada kelompok kontrol, semuanya juga tidak mengalami kejadian dekubitus, sejumlah 23 orang (100\%). Sebelum atau pre test itu dipilih oleh peneliti sesuai dengan kriteria eklusi yaitu tidak terjadi dekubitus.

Perawatan yang sudah dilakukan diruang IRIN sebelum dijadikan responden dalam penelitian yaitu alih baring setiap 2 jam. Pencegahan adalah cara terbaik yang dapat dilakukan oleh perawat terhadap pasien yang mengalami bedrest total. Tindakan tersebut adalah dengan melakukan alih baring merupakan perubahan posisi yang diberikan untuk mengurangi tekanan dan gaya gesek yang dapat melukai kulit serta menjaga daerah yang tertekan tidak mengalami luka (Potter \& Perry, 2012). Resiko dekubitus apabila tidak dicegah maka bagi pasien akan mengakibatkan peningkatan biaya perawatan, memperpanjang waktu perawatan, dan mengganggu proses rehabilitasi pasien. Kerugian yang didapat rumah sakit adalah mendapatkan stigma bahwa pelayanan yang diberikan kepada pasien buruk, baik bagi pasien itu sendiri, keluarga pasien maupun masyarakat umum (Potter \& Perry, 2010).

\section{Kejadian Dekubitus Sesudah Diberikan massage efflurage dengan virgin coconut oil pada Kelompok Intervensi dan Kontrol}

Diketahui bahwa sesudah diberikan terapi massage efflurage dengan virgin coconut oil ( $V C O$ ) pada kelompok intervensi, sebagian besar pasien tidak mengalami kejadian dekubitus, sejumlah 22 orang $(95,7 \%)$, sedangkan pasien yang mengalami kejadian dekubitus sejumlah 1 orang $(4,3 \%)$ terjadi pada usia $>60$ tahun sebanyak 1 pasien dengan tanda kemerahan, hangat, dan lecet. Beberapa faktor dapat menjadikan penyebab terjadinya dekubitus, salah satu faktor yang mempengaruhi resiko terjadinya dekubitus adalah adanya imobilitas, gaya gesek dan penurunan tingkat aktivitas pasien. Maka dari itu dengan adanya faktor tersebut akan berpengaruh terhadap kelembaban kulit akibat tekanan sehingga meningkatkan maserasi kulit, menyebabkan epidermis lebih mudah terkisis dan menghambat aliran darah (Kozier, 2010).

Luka dekubitus dapat disebabkan oleh paparan keringat, darah, urin dan feses (AlRasyid \& Misbach, 2015). Pasien imobilitas sangat rentan untuk terkena paparan keringat urine atau feses karena ketidakmampuan untuk mobilitas. Virgin Coconut Oil dapat diberikan sebagai bahan topikal yang berfungsi menjadi pelembab untuk mencegah kulit kering dan sebagai bahan topikal untuk meminimalkan paparan keringat berlebihan, urin atau feses karena sifatnya sebagai minyak yang tidak dapat bercampur dengan air (Setiani, 2014).

Menurut Nursalam (2011) pasien yang sudah tua memiliki resiko yang tinggi untuk terjadi dekubitus karena kulit dan jaringan akan berubah seiring dengan penuaan. Ayello dan Braden (2010) mengungkapkan bahwa resiko terjadinya dekubitus akan semakin besar ketika usia diatas $>60$ tahun. Dalam penelitian ini tidak hanya dilakukan pada usia lanjut, namun pada responden yang mengalami bedrest. Menurut Purwaningsih (2012) bahwa prevalensi dekubitus $40 \%$ domain pada usia $>60$ tahun. Penuaan mengakibatkan kehilangan otot, penurunan elastisitas kulit. 
Usia mempengaruhi perubahan-perubahan pada kulit. Proses menua mengakibatkan perubahan struktur kulit menjadi lebih tipis dan mudah rusak. Potter \& Perry (2012) menyatakan 60\% - 90\% luka tekan dialami oleh usia 65 tahun ke atas. Usia lanjut (lebih dari 60 tahun) dihubungkan dengan perubahan-perubahan seperti menipisnya kulit, kehilangan jaringan lemak, menurunnya fungsi persepsi sensori, meningkatnya fargilitas pembuluh darah, dan lain sebagainya. Perubahan-perubahan ini menurut Bryant (2010) mengakibatkan kerusakan kemampuan jaringan lunak untuk mendistribusikan beban mekanis. Kombinasi perubahan karena proses menua dan faktor lain menyebabkan kulit mudah rusak jika mengalami tekanan, shear, dan gesekan ( Bryant, 2010).

Pada kelompok kontrol yang tidak diberikan massage efflurage dengan Virgin Coconut Oil (VCO), sebagian besar pasien tidak mengalami kejadian dekubitus, sejumlah 15 orang $(65,2 \%)$, sedangkan pasien yang mengalami kejadian dekubitus sejumlah 8 orang $(34,8 \%)$ terjadi pada usia $>60$ tahun sebanyak 7 pasien $<60$ tahun sebanyak 1 pasien dengan tanda kemerahan, lecet, nyeri skala $1-3$. Responden diambil setelah masa rawat 3 hari sesuai dengan kriteria inklusi dan eklusi, dilakukan massage efflurage dengan virgin coconut oil selama 3 hari setiap selesai mandi pagi dan sore.

Menurut Perry \& Potter (2010) menyatakan bahwa setelah periode iskemik kulit akan menghasikan perubahan hiperemi. Hiperemi reaktif (kemerahan) ini merupakan respon tubuh normal terhadap kekurangan aliran darah pada jaringan dibawahnya. Terkait dengan intervensi keperawatan untuk pencegahan luka tekan, Potter \& Perry (2010) menyatakan ada 3 area intervensi keperawatan utama dalam pencegahan luka tekan yakni (pertama) perawatan kulit yang meliputi perawatan hygiene dan pemberian topikal, (kedua) pencegahan mekanik dan dukungan permukaan yang meliputi penggunaan tempat tidur, pemberian posisi dan kasur terapeutik dan (ketiga) edukasi.

Menurut asumsi peneliti kondisi fisik lemah, proses penyakit, usia, berat badan yang berlebih, penurunan kesadaran serta asupan nutrisi yang kurang adekuat, apabila tidak ada perhatian yang baik dari perawat akan mengakibatkan kerusakan integritas kulit, luka tekan sering terjadi pada pasien yang mengalami tirah baring lama. Untuk mencegah luka tekan atau dekubitus maka peneliti memberikan intervensi yaitu massage efflurage dengan virgin coconut oil.

Dari hasil penelitian (Prasetyo Dwi, 2017) yang berjudul pengaruh massage teknik effleurage terhadap tekanan darah pada penderita hipertensi di desa kalirejo kabupaten purworejo menunjukan hasil penelitian diperoleh bahwa pemberian massage teknik effleurage pada bagian punggung, dan ekstremitas atas pada penderita hipertensi di Desa Kalirejo Kabupaten Purworejo dapat menurunkan tekanan darah sistolik dari 156,60 mmHg menjadi $141,33 \mathrm{mmHg}$, dan tekanan darah diastolik dari $87,60 \mathrm{mmHg}$ menjadi 81,20 mmHg dengan nilai $\mathrm{p}$ value $=0.000(\mathrm{p}<0,05)$.

Peneliti memberikan massage efflurage dengan virgin coconut oil sehari 2 kali setelah pasien mandi pagi dan mandi sore. Beberapa responden penelitian pada kelompok kontrol juga menyatakan, pemakaian VCO tidak menimbulkan sensasi rasa panas di bagian punggung, area bokong dan bahu pada pasien yang berbaring terlentang. Penggunaan VCO dengan pijat tidak hanya dapat meningkatkan relaksasi otot dan meningkatkan sirkulasi, tetapi juga dapat meningkatkan absorbsi kandungan biologis VCO melalui kulit. Mituhu et al ( 2011) menyatakan bahwa tindakan massage efflurage dapat merubah tekanan dan melancarkan peredaran darah pada area tertekan sehingga mencegah dekubitus. 
Virgin Coconut Oil (VCO) telah diteliti bermanfaat bagi kesehatan kulit. Kandungan asam lemak (terutama asam laurat dan oleat) bersifat melembutkan kulit dan antimicrobial sehingga VCO efektif dan aman digunakan sebagai moisturizer pada kulit (Agero \& Verallo-Rowell, 2010; Lucida, Salman \& Hervian, 2010). Hasil penelitian ini menunjukkan analisis perbedaan kejadian luka tekan grade I pada responden yang diberi perawatan dengan $V C O$ dan responden yang diberi perawatan tanpa $V C O$ diperoleh kesimpulan ada perbedaan proporsi kejadian luka tekan grade $I$ antara responden yang diberi perawatan pencegahan dengan $V C O$ dan tanpa $V C O$ (ada perbedaan yang signifikan terhadap kejadian luka tekan grade $I$ antara responden yang diberi perawatan pencegahan dengan $V C O$ dan tanpa VCO; $p$ value $0,033<\alpha 0,05 ; R R 0,733 ; 95 \%$ CI $0,540-0,995)$. Sastroasmoro \& Ismail (2011), Hastono (2011) menyatakan nilai Ods Ratio (OR) atau Risk Relative (RR) berarti faktor yang diteliti bersifat protektif terhadap outcome. Dengan demikian artinya responden yang diberi perawatan dengan $V C O$ terlindungi sebesar 0,733 kali dari kejadian luka tekan grade $I$ dibandingkan dengan responden yang dirawat tanpa menggunakan $V C O$ dan dipercaya 95\% rentang kepercayaan berada pada 0,540 - 0,995 kali. Intervensi perawatan untuk mencegah terjadinya luka tekan pada pasien yang teridentifikasi berisiko merupakan kewajiban perawat. Upaya ini dilakukan sedini mungkin sejak pasien teridentifikasi berisiko (Rest Heaven, 2013).

Potter \& Perry (2010) menyatakan memberikan pelembab memang bukan intervensi utama untuk mencegah terbentuknya luka tekan. Namun, pencegahan luka tekan hanya melakukan perubahan posisi tanpa upaya mempertahankan toleransi jaringan kulit terhadap tekanan tidak memberikan hasil maksimal. Upaya mempertahankan atau memperbaiki elastisitas jaringan kulit, mencegah kulit kering atau lembab berlebihan, dan menjaga kebersihan kulit mendukung intervensi pencegahan luka tekan secara maksimal.

\section{Pengaruh Massage Efflurage dengan Virgin Coconut Oil (VCO) terhadap pencegahan dekubitus pada pasien Bedrest diruang Instalasi Rawat Intensive (IRIN)}

Hasil penelitian mendapatkan adanya pengaruh Massage Efflurage dengan Virgin Coconut Oil (VCO) terhadap pencegahan dekubitus pada pasien Bedrest diruang Instalasi Rawat Intensive (IRIN) karena nilai $\mathrm{p}(0,022)<\alpha(0,05)$. Luka dekubitus dapat disebabkan oleh paparan keringat, darah, urin dan feses (Al Rasyid \& Misbach, 2015). Pasien imobilitas sangat rentan untuk terkena paparan keringat urine atau feses karena ketidakmampuan untuk mobilitas. Virgin Coconut Oil dapat diberikan sebagai bahan topikal yang berfungsi menjadi pelembab untuk mencegah kulit kering dan sebagai bahan topikal untuk meminimalkan paparan keringat berlebihan, urin atau feses karena sifatnya sebagai minyak yang tidak dapat bercampur dengan air (Setiani, 2014).

Hasil penelitian yang dilakukan Handayani (2010) dan Dewandono (2014), menunjukkan bahwa VCO dengan massage dapat dijadikan sebagai salah satu intervensi mandiri keperawatan dalam intervensi pencegahan luka tekan atau dekubitus pada pasien yang berisiko mengalami dekubitus dengan hasil Hasil uji Fisher exact dan regresi logistik berganda menunjukkan adanya perbedaan kejadian luka tekan pada klien yang dirawat menggunakan VCO dengan pijat dibandingkan dengan klien yang dirawat tanpa VCO ( $\mathrm{p}=$ $0,033 ; \alpha=0,05 ; \mathrm{OR}=0,733 ; 95 \%$ CI $0,540-0,995)$ setelah dikontrol oleh variabel Indeks Massa Tubuh (IMT). 
Hasil penelitian Sunaryati (2014) terdapat perbedaan yang signifikan antara pemberian minyak kelapa dan pengetahuan reposisi pencegahan decubitus hasil uji chi square dengan fishers exact test menunjukkan bahwa terdapat pengaruh yang signifikan antara pemberian minyak kelapa dan pengetahuan tentang reposisi sebesar 0,021<0,05. Penelitian tentang masase punggung menggunakan minyak kelapa (VCO) oleh Setyawati (2012) dengan judul pengaruh mobilisasi dan penggunaan VCO (Virgin Coconut Oil) terhadap ulkus dekubitus pada gangguan motorik pasca stroke di RS Islam Sultan Agung Semarang. Kelompok intervensi dilakukan mobilisasi 2-3 jam sekali dengan memberikan VCO sedangkan kelompok kontrol dilakukan mobilisasi lebih dari 2-3 jam sekalidan tidak diberikan VCO. Hasil penelitian menunjukkan bahwa tidak terdapat perbedaan grade dekubitus pada kelompok intervensi dan kontrol yang dilakukan mobilisasi dan diberikan VCO dengan nilai $\mathrm{p}=0,495$.

\section{SIMPULAN DAN SARAN}

\section{Simpulan}

1. Usia Responden sebagian besar usianya $>60$ tahun sebanyak 25 orang sedangkan jenis kelamin responden paling banyak adalah perempuan 25 orang.

2. Sebelum diberikan terapi massage efflurage dengan virgin coconut oil pada kelompok intervensi dan kontrol semuanya tidak mengalami kejadian dekubitus.

3. Sesudah diberikan terapi massage efflurage dengan virgin coconut oil (VCO) pada kelompok intervensi terjadi dekubitus sebanyak 1 pasien. sedangkan pasien pada kelompok kontrol yang tidak diberikan massage efflurage dengan Virgin Coconut Oil (VCO) sebanyak 8 pasien.

4. Ada pengaruh secara signifikan massage efflurage dengan Virgin Coconut Oil (VCO) terhadap pencegahan dekubitus pada pasien bedrest di Ruang Instalasi Rawat Intensive (IRIN) RS Mardi Rahayu Kudus.

\section{Saran}

1. Bagi RS Mardi Rahayu Kudus

Hasil penelitian ini akan disampaikan kepada Kepala Pengendalian dan Pencegahan Infeks (PPI) dan Kepala Bidang Keperawatan untuk dijadikan SPO dlam melakukan asuhan keperawatan untuk menggunakan $V C O$ sebagai bahan topikal dalam perawatan kulit untuk mencegah dekubitus sebagai salah satu intervensi keperawatan mandiri yang efektif dan efisien.

2. Bagi Institusi Pendidikan

Hasil penelitian ini dapat berguna sebagai acuan dalam proses belajar mengajar mata kuliah keperawatan Medikal Bedah sehingga massage efflurage dengan virgin coconut oil (VCO) dapat mencegah terjadinya dekubitus pada pasien bedrest.

3. Bagi Peneliti Selanjutnya

Membandingkan efektivitas penggunaan VCO dengan bahan topikal atau pelembab lain seperti lotion atau sediaan krim lain.

Peneliti lain mempertimbangkan menambah sampel dan lama penelitian. 


\section{DAFTAR PUSTAKA}

Amir,Yufitriana. (2015). Quality Of Pressure Ulcer Care In Indonesia Hospitals Dissertation .http //nl. Lpz-um.eu/ content/ public/nl/publication.pdf

Ardiansyah, Muhammad. (2012). Medical Bedah Untuk Mahasiswa. Yogyakarta: Diva Press

Braden, B.,\& Bergstrom,N. ( 2010 ). A conceptual schema for the study of the etiology of pressure sores. Rehabilitation Nursing .

Bryan, R. A. (2010). Acute and cronic wound Nursing Management, second edition. Missouri, St Louis : Mosby Inc.

Carville, K. ( 2010 ). Wound care manual fifth edition. Western Australia : silver chain foundation.

Dewandana, Irawan Derajat. (2014). Pemanfaatan VCO (Virgin Coconut Oil) Dengan Teknik Massage Dalam Penyembuhan Luka Decubitus Derajat II Pada Lansia.Skripsi Stikes Kusuma Husada . Surakarta.

EPUAP, NPUAP. (2014). Pressure ulcer prevention quick reference guide. http://www.epuap.org/guidelines/Final_Quick_Prevention.pdf. Diakses 12 Januari 2018.

Fatonah. (2013). Efektifitas Penggunaan Virgin Coconut Oil (VCO) secara Topikal untuk Mengatasi Luka Tekan (Dekubitus) Grade I Dan II. Skripsi.

Handayani (2010), Efektifitas Penggunaan Virgin Coconut Oil (VCO) Dengan Massase Untuk Pencegahan Luka Tekan Grade I Pada Pasien Yang Beresiko Mengalami Luka Tekan di RSUD Dr. Hi. Abdoel Moeloek Provinsi Lampung.

Handayani et al. (2011). Pencegahan Luka Tekan Melalui Pijat Menggunakan Virgin Coconut Oil. Jurnal Keperawatan Indonesia, Volume 14, No. 3, November 2011; hal.141-148.

Hapsari, N. (2010). Pembuatan Virgin Coconut Oil (VCO) Dengan Metode Sentrifugasi. Jurnal, Teknik Kimia UPN Veteran, Surabaya.

Hastuti, Sri dkk. (2013). Faktor - Factor Yang Berhubungan Dengan Kejadian Decubitus Pada Pasien di Ruang Intensive Care Unit Rumah Sakit Ibnu Sima Makasar.2 (5):39-45.

Henny Syapitri, Laura Mariati Siregar dkk. (2017). Metode Pencegahan Luka Decubitus Pada Pasien Bedrest Total Melalui Perawatan Kulit

Huda, N. H. (2012). Pengaruh Posisi Miring Untuk Mengurangi Luka Tekan Pada Pasien Dengan Gangguan Persyarafan. Jurnal Keperawatan STIKes Hang Tuah Surabaya. Vol.3 No.2. April 2012.

Irawan. (2014). Pemanfaatan VCO Dengan Teknik Massage Dalam Penyembuhan Luka Dekubitus Derajat 2 Pada Lansia. Skripsi. Stikes Kusuma Husada Surakarta.

Kozier. (2010). Buku Ajr Fundamental Keperawatan: Konsep, Proses dan Praktik. Jakarta. EGC.

Marina et al. (2015). Pencegahan Kejadian Luka Tekan Melalui Masase Virgin Coconut Oil Pada Pasien dengan Imobilisasi. Nursing Current Vol. 1 Januari 2013-Juni 2013.

Mutia et al. (2015). Profil Penderita Ulkus Dekubitus Yang Menjalani Tirah Baring DiRuang Rawat Inap RSUD Arifin Achmad Provinsi Riau Periode Januari 2011Desember 2013. JOM FK Volume 2 No. 2 hal. 1-11. 2015. 
National Guideline Clearinghouse (NGC) \& Institute for Clinical Systems Improvement (ICSI). 2010. Pressure ulcer prevention and treatment. Health Care Protocol.Bloomington (MN): Institute for Clinical Systems Improvement (ICSI).

National Pressure Ulcer Advisory Panel. (2014). European Pressure Ulcer Advisory Panel and Pan Pacific Pressure Injury Alliance. Prevention and Treatment of Pressure Ulcers: Quick. Reference Guide. Emily Haesler (Ed.). Cambridge Media: Perth, Australia.

Notoatmodjo, Soekidjo. (2012). Metodologi Penelitian Kesehatan . Rineka Cipta : Jakarta.

Nursalam. (2013). Konsep Penerapan Metode Penelitian Ilmu Keperawatan. Jakarta: Salemba Medika.

Potter, Patricia A. \& Perry. (2015). Buku Ajar Fundamental Keperawatan: Konsep, Proses dan Praktik. EGC, Jakarta

Potter, P. A \& Perry, A. G. (2010). Fundamental of Nursing, Eight Edition. Canada: Mosby Elsevier.

Rajamohan, T; Kevin, K.G. (2010). Effect of topical application of Virgin Coconut Oil on skin component and antioxidant status during dermal wound healing in young rats. Journal of Pharmacology \& Bhiophysical Research. Vol 23, No 6 2010.Abstract. http://content.karger.com/ProdukteDB/produkte.asp?Doi=313516

Rismawan, W. (2014). Hubungan Tingkat Pengetahuan Keluarga Klien Tentang Pencegahan Dekubitus Terhadap Kejadian Dekubitus Pada Pasien Bedrest Total Di RS Dr. Soekardjo Tasikmalaya Kota Tasikmalaya. Jurnal Kesehatan Bukti Tunas Husada Volume 12 No. 1, hal. 112-127.

Riwidikdo, Handoko. (2015). Statistic Kesehatan, Mitra Cendekia Press : Yogyakarta.

Santoso , Imam. (2013). Managemen Data. Gosyen Publishing. Yogyakarta.

Santoso, (2014). Pengaruh Alih Baring Terhadap Kejadian Dekubitus Pada Pasien Stroke Yang Mengalami Hemiparesis di Ruang Yudistira di RSUD Kota Semarang. Skripsi. Stikes Ngudi Waluyo.

Setiani, D. (2014). Efektivitas Massage Dengan Virgin Coconut Oil Terhadap Pencegahan Luka Tekan Di Intensive Care Unit. Jurnal Husada Mahakam Volume III No. 8, hal.389-442.

Sihombing et al. (2016). The Effectiveness of Back Massage Using Virgin Coconut Oil and White Petroleum Jelly To Prevent Pressure Sores. Jurnal Keperawatan Muhammadiyah, 1(2), hal. 1-9 